\title{
Occurrence and Infestation of Coffee Leaf Skeletonizer, Leucoplema Dohertyi (Warren) on Young Coffee Seedlings at Jimma Ethiopia
}

\author{
Sisay Kidanu*, Sisay Tesfaye \\ Ethiopian Institute of Agricultural Research, Jimma Agricultural Research Center Jimma, Ethiopia \\ *Corresponding Authors: Sisay Kidanu, Ethiopian Institute of Agricultural Research, Jimma \\ Agricultural Research Center Jimma, Ethiopia
}

\begin{abstract}
Coffee production in Ethiopia is expanding to non-traditional geographical areas without sufficient information on the influence of insect pests on coffee production. With the existence of some preliminary studies on minor pests, the economic importance of minor coffee insect pests in relation to weather factors in Ethiopia both under controlled and field conditions yet require more detailed studies. This study was conducted to understand the nature of damage and assess the level of infestation for coffee leaf skeletonizer on coffee seedlings planted in green house. The result showed that different degree of infestation ranged $35.29-$ $85.11 \%$ was recorded. On the other, the number of pupae per seedling was various in different seedling pots with range of $0.04-0.21$. Thus this study calls understanding the potential impacts of leaf feeders insect pests of coffee in relation to climatic variables at seedling stage is crucial.
\end{abstract}

Keywords: Abundance, coffee seedlings, leaffeeder

\section{INTRODUCTION}

Coffee is one of the highly preferred international beverages and the most important traded commodities in the world next to petroleum (FAO, 2015). Coffee is the most important export commodity for Ethiopia and it accounts for about 34\% of value of all exports (FAS, 2019). Coffea arabica $\mathrm{L}$. is the most widely cultivated coffee species in the world, which accounts for about $58.68 \%$ of world coffee production (UCDA, 2019). More than 125 million people worldwide are deriving their income directly or indirectly from its products in cultivation, processing, trading, transportation and marketing (Mishra and Slater, 2012).

In Ethiopia, the coffee is important to the economy of the country which is used as source of foreign income and also millions of the population relying on coffee production for their livelihood (ECTA, 2018). Nationally, it is estimated that there are around 5,270,777 households participated in coffee production activities. However, an estimated over 25 million people are engaged at least on coffee production, distribution, trading, processing, exporting and other support and downstream activities (ECTA, 2018). It also accounts for 25-30 \% of Ethiopia's total export earnings, $5 \%$ of the gross domestic product (GDP) and about $50 \%$ of the total production for domestic consumption(ECTA, 2018).

Insect pests cause up to $20 \%$ of crop loss and reduce coffee value by 30 to $40 \%$ (Pablo et al., 2012). Although Ethiopia is the homeland for Arabica coffee and the environmental conditions are suitable for coffee production, the average national yield is very low. Insect pests are among the factors considered to limit coffee production in both quality and quantity (Million and Bayissa, 1986; Million, 1987; 2000). Over 47 species of insect pests are recorded on coffee in Ethiopia (Crowe and Tadesse, 1984; Million and Bayissa, 1986), among which the antestia bugs (Antestiopsis intricate and A. facetoides) and coffee blotch miner (Leucoptera caffeina) are the major ones inflicting considerable damage. Moreover, insect pests such as coffee berry borer, (Hypothenemus hampei), coffee thrips (Diarthrothrips coffeae), green scale (Coccus alpinus) and coffee cushion scale (Stictococcus formicarius) are potentially important pests which can cause serious damage when conducive factors met.

Eminent scientists/Climatologists are warning the world, that the global warming is increasing worldwide resulting with the rise of temperature everywhere (Yilma, 2019). Nowadays, numbers of 
insect pests previously considered as minor are becoming major and there is change of status in occurrence, distribution and development among coffee insect pests known in Ethiopia. The probable cause for such shifting may be the current climate change scenario and the shift from traditional to modern (intensive) farming systems, hence the existing and increasing change in dynamism of insect pests in general and coffee insect pests specifically demand for updated information, enabling to pay due attention. In this regard among the Coffee attacking insect pests known to severely to occur in all leaf producing growth stage of coffee (Leaf skeletonizer) and prevalent in either farming systems (Forest, Semi forest, Garden, Modern), was assessed under green house environment aiming to estimate the prevalence/abundance at seedling stage.

\section{Materials AND Methods}

\subsection{Description of the Study Area}

The study was undertaken at Jimma Agricultural Research Center (JARC) coffee protection research green house in 2020 . JARC is located at $07^{\circ} 46^{\prime} \mathrm{N}$ latitude and $36^{\circ} 47^{\circ} \mathrm{E}$ longitude coordinate and at an elevation of 1753m.a.s.l. The site is 360 kilometer away from Addis Ababa, the capital of Ethiopia and 12 kilometers west of Jimma town. It is situated in the tepid to cool humid mid highlands of South Western Ethiopia which receives annual rainfall of $1572 \mathrm{~mm}$. Its mean minimum and maximum temperature is $11.6^{\circ} \mathrm{c}$ and $26.3^{\circ} \mathrm{c}$, respectively. The major soil type of the area is Eutric Nitosol and Cambisoil (reddish brown) of upland and fluvisol of bottom land with pH of around 5.2 (IAR, 1997).

\subsection{Coffee Seedling Raising}

Seeds from Geisha coffee variety were planted in July, 2018/19 in $0.19 \mathrm{~m} 2$ pot following the standard coffee Arabica seedling raising protocol. Fifty pots were raising in a single $2.5 \mathrm{~m} \times 1.5 \mathrm{~m}$ cemented block and totally three cemented blocks were used for 150 pots seedling raising. In each pot six seedlings were raised.

\subsection{Data collection}

From each cemented block ten seedling pots were randomly selected and from each pot three seedlings were considered for study. Therefore totally from the three cemented blocks consisting optimum of 50 pots, thirty from each block and a total of ninety coffee seedlings were selected randomly for coffee leaf skeletonizer infestation and pupae abundance assessment. Infestation and pupae abundance were calculated using the following formula,

Infestation $=\underline{\text { Number infested leaf }} * 100$

Total number of sampled leaf

Pupae abundance $=$ Number pupae collected

Total number of sampled seedlings

\section{RESUlT AND DISCUSSION}

Coffee leaf skeletonizer, Leucoplema dohertyi (Warren) a Lepidoptera attacking coffee leaves both in field and at seedling stages. The larvae feed on the underside of leaves, usually near the midrib eating everything except the veins and the upper epidermis, leaving irregular lace-like patches in the leaf. The occurrence of this insect in the glass house was abundantly found during the assessment. The overall mean of infestation showed high in all pot coffee seedling ranged from $55.0-74.42 \%$ planted in block A (Fig. 1a). This showed that the infestation is various and serious by this insect in all assessed seedlings. On the other the mean number of leaf skeletonizer pupae per seedling or pupae abundance recorded ranged from $0.06-0.14$ (Fig 1b). According to a report of surveys conducted in Southwestern Ethiopia showed variation of incidences of coffee leaf skeletonizer was recorded with a mean leaf damage of $15.4 \%$ (Esayas, unpublished). 

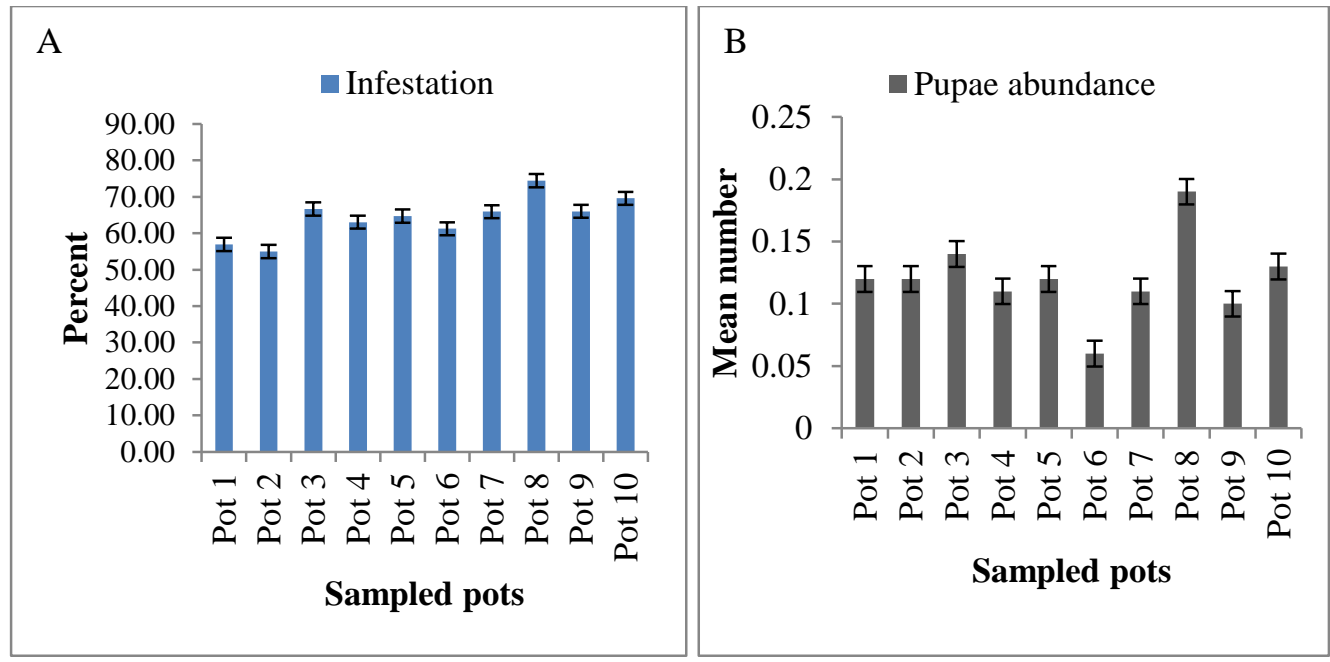

Fig1. Infestation and number of pupae of coffee leaf skeletonizer in green house (From block A)

Similarly, coffee seedling in block B showed different level of infestation with a relatively higher level compared to in block A with a mean range of $55.6-85.11 \%$ and the mean number of pupae on seedlings in block B is $0.04-0.21$ (Fig. 3a \& b). This is may be due variation in population density of seedling since very few seedlings in blocks $\mathrm{A}$ and $\mathrm{C}$ were lossed due to other factors such as damping off. According to Ugandan coffee development authority, coffee leaf skeletonizer one of the major insect pest frequently damage as an outbreaks at nursery station but minor in the fields especially on coffee robusta in Uganda feed under surfaces of leaves leaving veins and upper epidermis to create window like patches (UCDA, 2019).

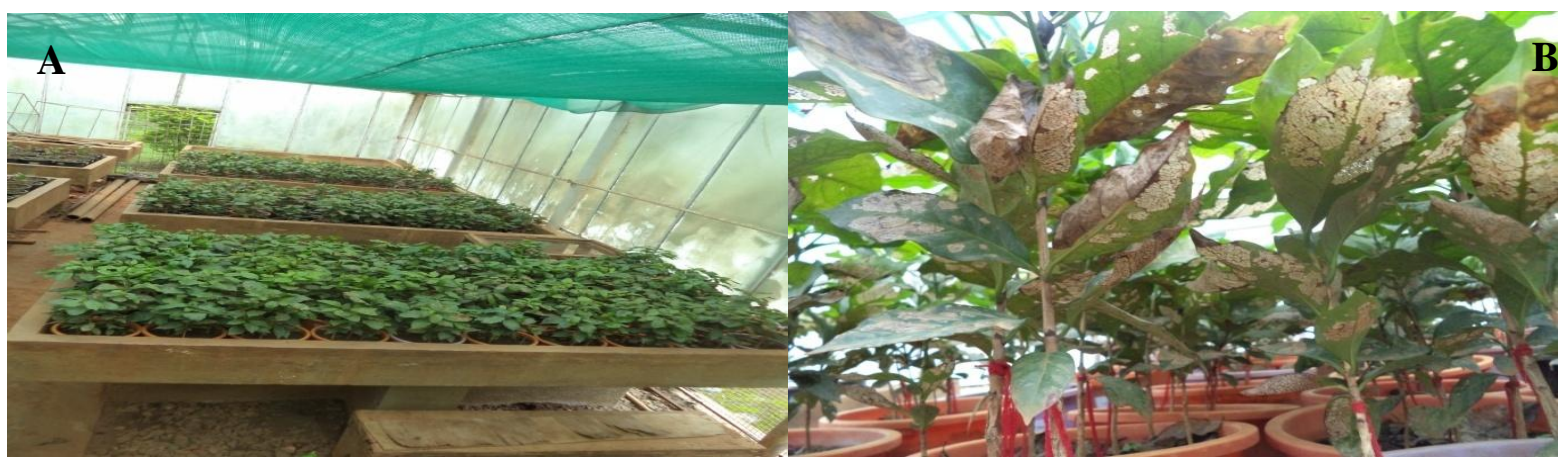

Fig2. Coffee seedling in pots raised in three cemented blocks (A), Leaf skeletonizer Infestation in Block 1 (B)

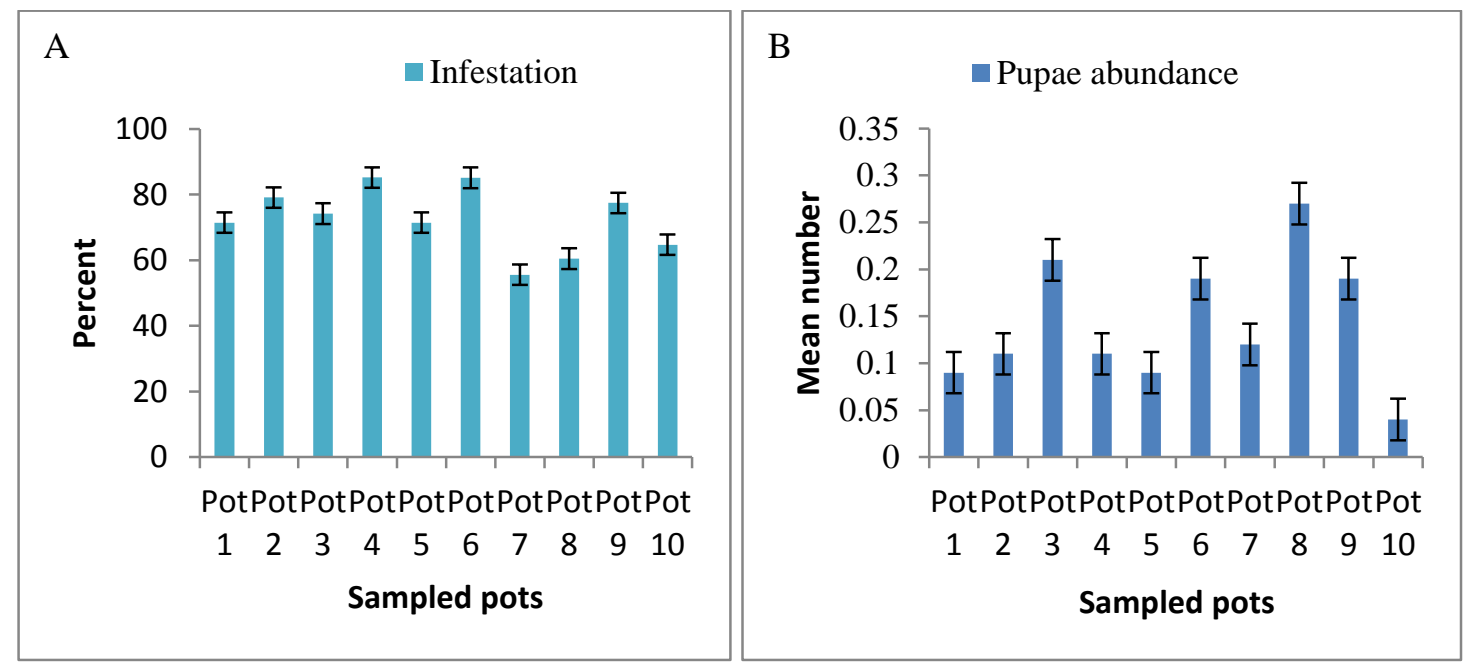

Fig3. Infestation and number of pupae of coffee leaf skeletonizer in green house (From block B) 


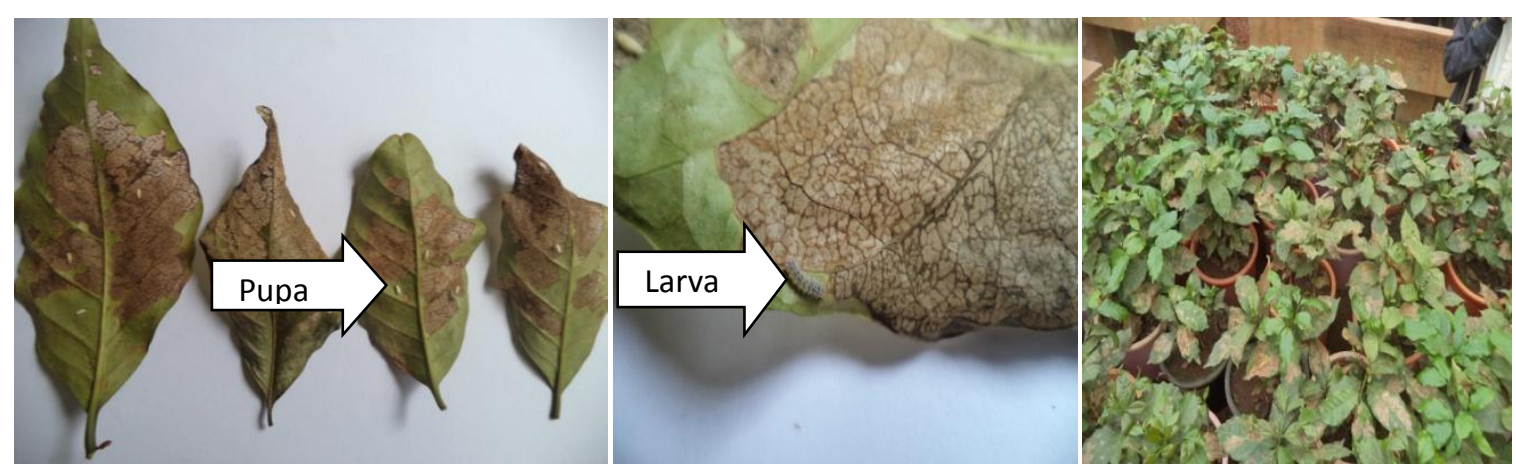

Fig4. Pupae and larvae of leaf skeletonizer on assessed coffee seedlings and the damage

Coffee leaf skeletonizer also infested seedlings planted in block $\mathrm{C}$, showed variability among seedling both infestations level and number of pupae. The infestation is ranged from $35.29-72.97 \%$ and from $0.06-0.16$ number pupae per seedling (Fig. 5a \& b).

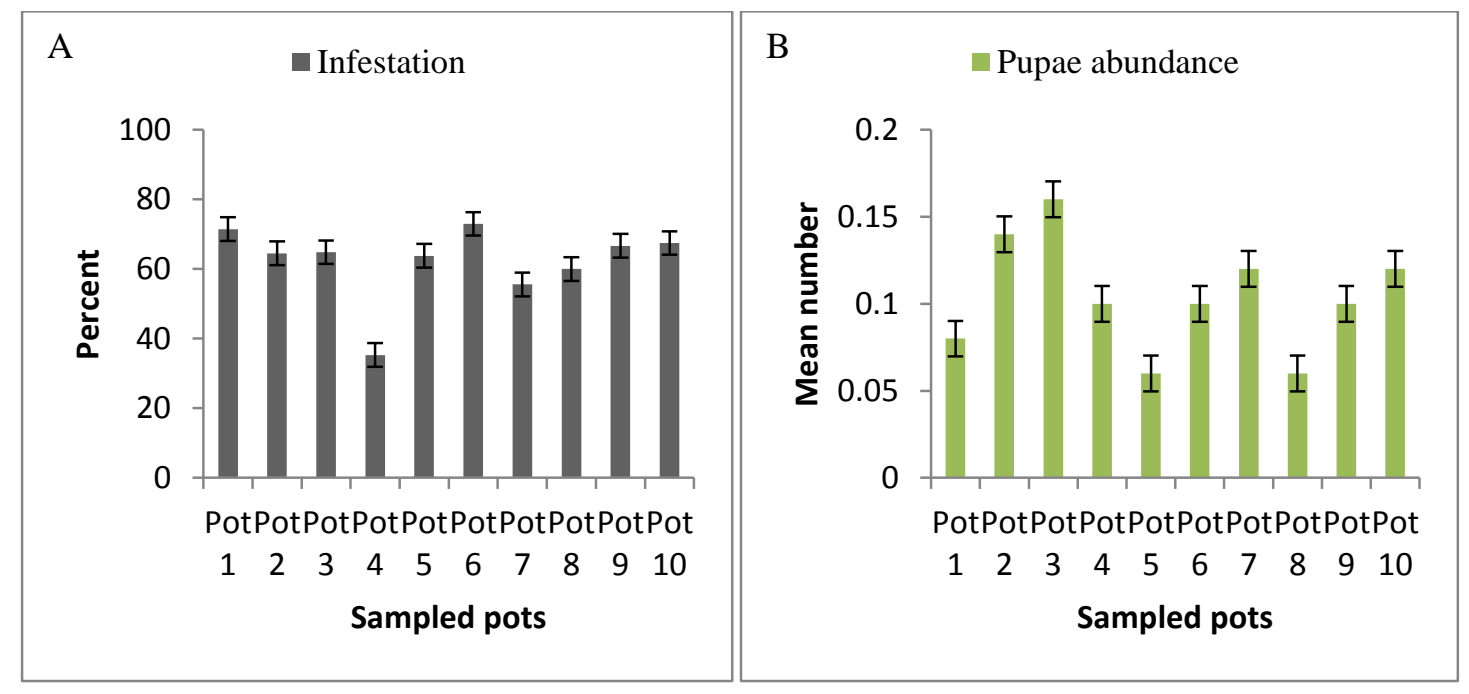

Fig5. Infestation and number of pupae of coffee leaf skeletonizer in green house (From block C)

Leaf damaging insect pests like coffee leaf skeletonizer was reported in Southwestern Ethiopia, with different mean proportion (Fuad, 2010; Chemeda et al., 2015). Fuad (2010) stated that the leaf damage proportion on wild coffee was $53 \%$ for leaf skeletonizer. The above author also stated the mean incidence of leaf damaging insects during wet (31.2\%), transition (31.9\%) and dry (17.62\%) season, and the least was recorded during dry season. Similarly, in Southwestern Ethiopia the abundance of coffee leaf skeletonizer, $100 \%$ of plots, (Samnegard et al., 2014). Also, the mean leaf damage of 2.7 to $31.76 \%$ by coffee leaf skeletonizer was recorded in Southwestern and Western coffee growing areas of Ethiopia (Tamiru et al., 2017). A study conducted by Crowe and Tadesse (1984) reported that larvae a grey/white caterpillar with many pimple-like projections on the body and finally after pupation a grey/brown adult moth with a wing span emerge. According to Crowe and Tadesse (1984) recommendation the insect can be controlled by fenitrothion $50 \%$ E.C or fenithion $50 \%$ E.C foliar spray.

\section{CONCLUSION}

The issue of degree of infestation fluctuation of minor insect pests of coffee has becoming a more threatening to sustainable development because nowadays minor insect pests become major, uncommon became common pests. It is important updating previous chemical control recommendation. Therefore research attention should be given to bio ecological studies in relation with climate change.

\section{ACKNOWLEDGEMENT}

We are grateful Mr. Sebsibe and Abafita for their immeasurable help during data collection. 


\section{REFERENCES}

[1] Chemeda A., E. Getu, E. Seyoum, and Hindorf H. \& T. Berhane. 2015. Coffee leaf damaging insects occurrence in the forest coffee ecosystem of southwestern Ethiopia. African Journal of Plant Science, 9(2):75-81.

[2] Crowe, T. J. \& T. Gebremedhin. 1984. Institute of Agricultural Research Coffee Pests in Ethiopia Their Biology and Control. http://hdl.handle.net assessed, October, 2018.

[3] ECTA (Ethiopian Coffee \& Tea Authority PR \& Communication Team). 2018. Economic Benefit of Ethiopian Coffee page 1-6. http://www.aigaforum.com/article2018/Economic-Benefit-of-EthiopianCoffee.pdf assessed in August 12, 2019.

[4] FAO. 2015. The State of Food Insecurity in the World. The Multiple Dimensions of Food Security. Food and Agriculture Organisation, Rome.

[5] FAS (Foreign Agricultural Service ). 2019. Coffee Annual Report. GAIN Report: ET1904.

[6] Fuad A. 2010. Studies on the diversity of insect pests in wild and cultivated coffee plantations in and around Jimma, southwest Ethiopia. An MSc. Thesis. Addis Ababa University, Addis Ababa. 67p.

[7] IAR (Ethiopian Agricultural Institute). 1997. Jimma National Coffee Research Center progress report for the period 1994 (Part 1 Coffee). Melko.

[8] Mishra, M. K, \& Slater A.. 2012. Recent Advances in the Genetic Transformation of Coffee, Review Article. Biotechnology Research International doi:10.1155/2012/580857

[9] Million, A. 1987. Insect pests of coffee with special emphasis on Antestia, Antestiopsis intricata in Ethiopia. Insect Science and its Application 8: 977-980.

[10] Million, A. 2000. Significance of arthropod pests of coffee in Ethiopia In: Proceedings of Workshop on the Control of CBD in Ethiopia, 13-15 August 1999. Addis Ababa: IAR: 66-71.

[11] Million, A. \& Bayisa M. 1986. A review of coffee insects and their control in Ethiopia. In: Proceeding of the first Ethiopian crop protection symposium, 4-7 February 1985, (Tsedeke, A., ed.). Addis Ababa, Ethiopia: $163-174$.

[12] Pablo B, Carmenza G, \& Alex B. 2012. IPM program to control coffee berry borer Hypothenemus hampei with emphasis on highly pathogenic mixed strains of Beauveria bassiana, to overcome insecticide resistance in Colombia.pp.511-539. In: Farzana Perveen (ed.), Insecticides -Advances In Integrated Pest Management, Rijeka,Croatia.

[13] Samnegard, U., Hamback, P.A., Nemomissa, S. \& Hylander, K. 2014. Local and regional variation in local frequency of multiple coffee pests across a mosaic landscape in Coffea arabica's native range. Biotropica, 46(3):276-284.

[14] Tamiru, S., Sisay, K., Balay, A. \& Demelash, T. 2017. Survey on Status of Key Coffee Insect Pests in Major Coffee Growing Areas of Ethiopia, International Journal of Research Studies in Science, Engineering and Technology volume 4 (9): 17-21.

[15] UCDA (Ugandan Coffee Development Authority). 2019. Clonal Robusta Coffee Nursery Manual for Extension Workers and Nursery Operators in Uganda, pp58.

[16] Yilma Yemaneberhan. 2019. Global Warming and future of Ethiopian Coffee. In: Esayas, M, Gezahegn B, Getachew W. \& Taye K eds. Proceedings of the Ethiopian Coffee Science Society (ECSS), enhancing coffee science and Technology for sustainable development in Ethiopia. Inaugural conference held on $7 \&$ 8 April 2017, Jimma, Ethiopia, P 292.

Citation: Sisay Kidanu \& Sisay Tesfaye, "Occurrence and Infestation of Coffee Leaf Skeletonizer, Leucoplema Dohertyi (Warren) on Young Coffee Seedlings at Jimma Ethiopia” International Journal of Research Studies in Agricultural Sciences (IJRSAS), 2020; 6(7), pp. 19-23, http://dx.doi.org/10.20431/24546224.0607003

Copyright: () 2020 Authors. This is an open-access article distributed under the terms of the Creative Commons Attribution License, which permits unrestricted use, distribution, and reproduction in any medium, provided the original author and source are credited. 